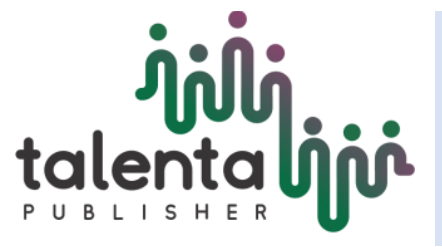

\section{AANHS Journal}

Journal of Medical Science

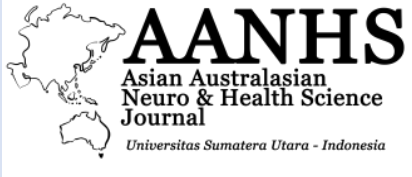

\title{
A Case Report: Massive Subdural Empyema Following Ventriculo-Peritoneal Shunt Placement in Child Patient
}

\author{
Nindi Lizen ${ }^{1}$, Abdurrahman Mouza ${ }^{1}$ \\ ${ }^{1}$ Department of Neurosurgery, Universitas Sumatera Utara, Medan, Indonesia
}

\begin{abstract}
Background: Subdural empyema is a critical neurosurgical condition that arise from neurosurgical procedures, trauma, meningitis, sinusitis, or otogenic infection. Reported mortality rates vary from $4.4 \%$ to $24 \%$. Ventriculoperitoneal (VP) shunt placement is one of the most common procedures and reported rates for shunt infections are relatively high. However, their association with subdural empyema is rare.

Case Report: One years old boy who presented with fever, lethargy, and inability to walk was admitted to the hospital. He was undergone Vp-shunt 1 month ago because of hydrocephalus. At the time of admission, the child was alert, had a moderate right hemiparesis, and a macrocephalic appearance. An emergency CT scan showed well-circumscribed subdural empyema.

Discussion: A craniotomy was performed, then thick fibrous capsule underlying the dura mater was encountered, finally the pus was totally removed. Postoperatively, he was fully alert with a marked motoric improvement. Diplococus gram positive was found. The patient was given appropriate antibiotic treatment for 3 weeks periode.

Conclusion: Subdural empyema is an unusual complication of a VP-shunt. Although rare in children, it is still a neurosurgical problem. The combination of medication and surgery treatment in Subdural empyema resulted in a good response.
\end{abstract}

Keywords: Subdural Empyema, Pediatric, VP-Shunt, Infection

\section{Introduction}

Subdural empyema (SDE) is a collection of purulent material between the dura mater and the arachnoid mater that usually occurs secondary to middle ear infection, meningitis, brain surgery, paranasal sinusitis, head trauma, or via hematogenous spread [1][2]. SDE is a critical neurosurgical condition that has mortality rates vary from $4.4 \%$ to $24 \%$ [1][2]. Ventriculoperitoneal (VP) shunt placement is one of the most common procedures in neurosurgery. The occurrence of SDE as a complication of a ventriculoperitoneal (VP) shunt infection is rare. Moreover, the reported rates for shunt infections are relatively high[3][4]

*Corresponding author at: Department of Neurosurgery,Universitas Sumatera Utara,Medan, Indonesia

Copyright @ 2020 Published by Talenta Publisher, ISSN: 2686-0848 ; DOI : 10.32734

Journal Homepage: http://aanhsj.usu.ac.id 


\section{Case Report}

One years-old boy who presented with fever, lethargy, and inability to walk since 1 weeks before admission at the hospital. He was undergone ventriculo-peritoneal shunt 1 month ago because of hydrocephalus. At the time of admission, the child was alert, had a moderate right hemiparesis, and a macrocephalic appearance with a head circumference of $52.5 \mathrm{~cm}$. Head CT-scan was seen ini figure 1 and figure 2.

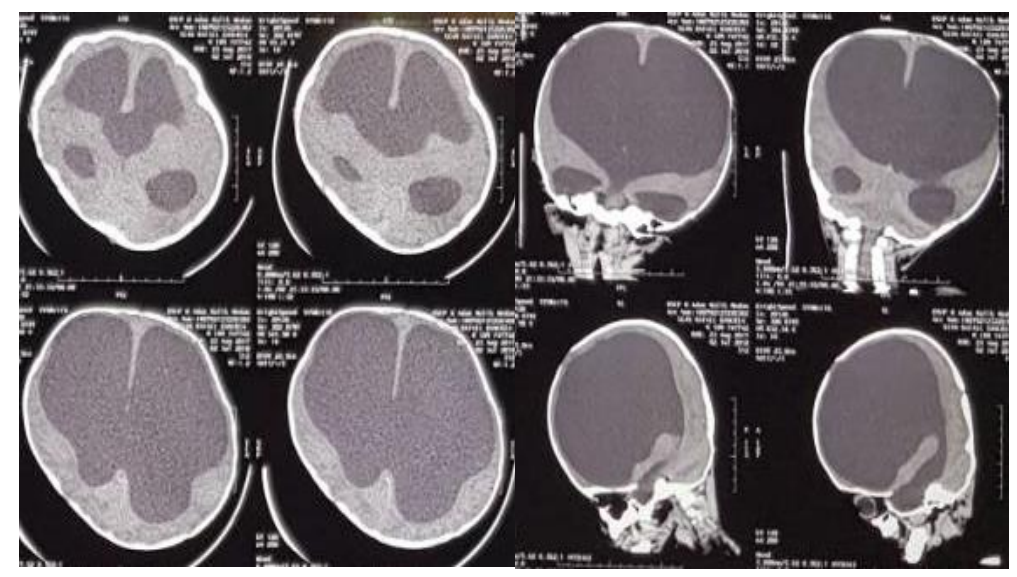

Figure 1. Non-Contrast Head CT-Scan of Patient before VP-shunt Procedure

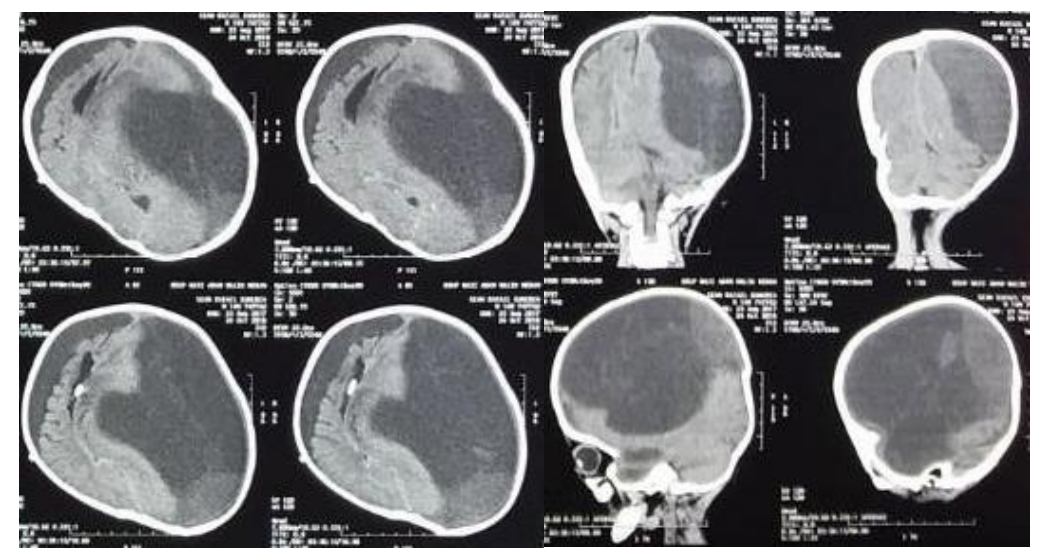

Figure 2. Non-Contrast Head CT-Scan of Patient 1 Month after VP-shunt Procedure

A craniotomy was performed in this patient. The duramater was opened and a thick fibrous capsule underlying the duramater was encountered. The pus was totally removed. Fully intraoperative view would see at figure 3. Post operative patient with GCS 15 and improvement in paresis (figure 3). 


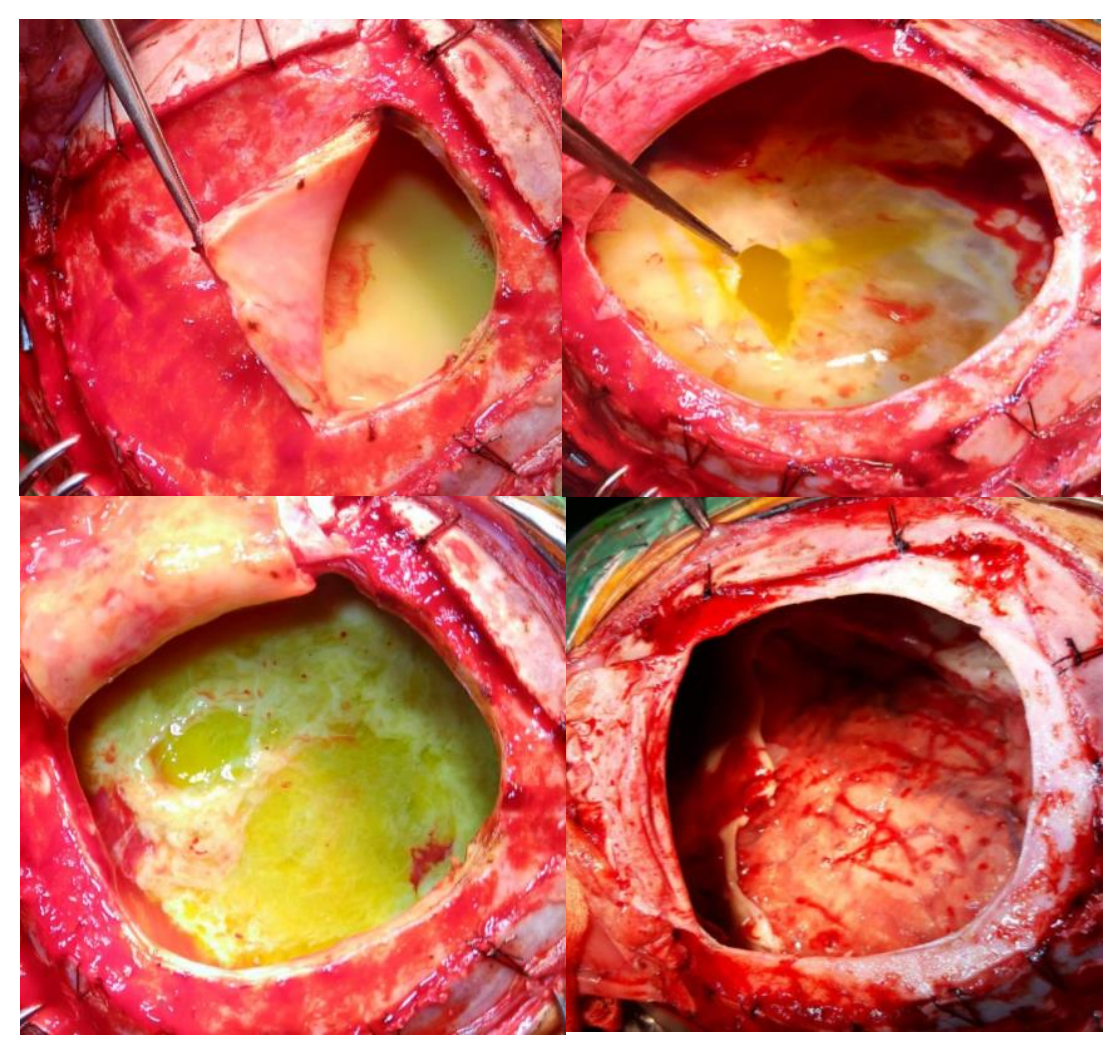

Figure 3. Intraoperative View

\section{Discussion}

Ventriculoperitoneal (VP) shunt placement is one of the most common procedures in neurosurgery [5][6]. This hydrocephalus treatment is often complicated by infection. However, subdural empyema is rare complication after following this treatment[7][8]. Intracranial subdural empyema may cause headaches, fevers, altered mental status, motor deficits, and seizures. A VPshunt infection is typically diagnosed after a workup that includes a CT head, a shunt series, and shunt reservoir tap[9][10]. Our patient presented at hospital with fever, lethargy, and inability to walk after had a Vp-shunt procedure 1 month ago. Based on non-contrast Head CT-Scan shows a right hemispheric calcified empyema then perfomed craniotomy and pus was totally removed. Diplococus gram positive was found from the pus. The patient was given appropriate antibiotic treatment with levofloxacin and metronidazole for 3 weeks periode. he was fully alert with a marked improvement of the left hemiparesis after combination treatment, definitive antimicrobial therapy and surgical procedure. 


\section{Conclusion}

Subdural empyema is an unusual complication of a VP shunt. Although rare in children, it is still a neurosurgical problem. Possible etiology may be local wound infection that seeds the subdural space and travels to the cranium, leading to meningitis and subdural empyema. This case demonstrates that Subdural empyema may reach a giant size and thus may mimic an intra-axial lesion in emergency axial CT scans. The combination of medication and surgery treatment in Subdural empyema resulted in a good response, fully alert with a marked improvement of the left hemiparesis. 


\section{References}

[1] Nguyen HS, et all. "Co-presentation of a subdural empyema and an infected ventriculoperitoneal shunt in an adult patient: A rare complication with review of literature”. Surgical Neurology International. 2015. Doi: 10.4103/2152-7806.166785

[2] Nguyen HS, Foy A, and Havens P. "Intracranial subdural empyema after surgery for lumbar lipomyelomeningocele: a rare complication”. Surgical Neurology International. 2016. Doi: $10.4103 / 2152-7806.182388$

[3] McGirt, et all. "Risk Factors for Pediatric Ventriculoperitoneal Shunt Infection and Predictors of Infectious Pathogens". Clinical Infectious Diseases. 36:858-62, 2003. PMID: 12652386

[4] Mohameth, F. et all. "Giant Calcified Subdural Empyema, a Complication of Ventriculo Peritoneal Shunt: Surgical Management and Revue of Literature”. Open Journal of Modern Neurosurgery. 10, 203-207, 2020. Doi: 10.4236/ojmn.2020.102021

[5] Gunawan PI and Suryaningtyas W. "Giant subdural empyema following ventriculoperitoneal shunt in a child". Pan African Medical Journal. 26: 120, 2017. Doi: 10.11604/pamj.2017.26.120.11866

[6] Murgas YG and Snowden JN. "Ventricular shunt infections: Immunopathogenesis and clinical management”. J Neuroimmunol. 276(0): 1-8, 2015. Doi: 10.1016/j.jneuroim.2014.08.006

[7] Dickerman RD, Piatt JH, Hsu F, and Frank EH. Subdural empyema complicating cerebrospinal fluid shunt infection. Pediatr Neurosurg. 30(6): 310-1, 1999. Doi: $10.1159 / 000028816$

[8] Hussain RA, Sainuddin S, Bhatti I, and Leach, P. Ventriculo-peritoneal shunt independence following successful treatment of Gram negative (E. coli) ventriculitis: Case report and review of the literature. Br J Neurosurg. 30(4):459-60, 2016. Doi: 10.3109/02688697.2015.1096908

[9] Gunawan PI, Kartina L, Puspitasari D, and Erny E. "Uncommon Pathogen Bacillus Cereus Causing Subdural Empyema in a Child". Ethiop J Health Sci. 28(1): 97-100, 2018. Doi: 10.4314/ejhs.v28i1.12 
[10] Tunkel, et all. “2017 Infectious Diseases Society of America's Clinical Practice Guidelines for Healthcare-Associated Ventriculitis and Meningitis”. Clinical Infectious Diseases. 64(6): e34-e65, 2017. Doi: 10.1093/cid/ciw861 